\title{
NA TRILHA DO MONDE DIPLOMATIQUE: UMA INTERNACIONALIZAÇÃO DA IMPRENSA À FRANCESA
}

\author{
Le Monde Diplomatique’s trajectory
}

La trayectoria de Le Monde Diplomatique

\begin{abstract}
Juliana Sayuri Ogassawara
Jornalista, doutora em História Social pela USP, pós-doutoranda em História pela UFSC julianasayuri.o@gmail.com
\end{abstract}

\section{Resumo}

Ancorado na história dos intelectuais, na história política e na história do tempo presente, este artigo aborda o processo de internacionalização do periódico francês Le Monde Diplomatique, destacando como seus jornalistas e intelectuais contribuíram para a consolidação da linha editorial da publicação. Fundado em 1954, em Paris, por Hubert Beuve-Méry, Le Monde Diplomatique teve suas ideias alastradas por diversos países - em fevereiro de 2013, o magazine tinha mais de 40 edições internacionais, entre versões impressas e estritamente eletrônicas, considerado um fenômeno único na imprensa internacional. Ao longo de sua trajetória, Le Monde Diplomatique teve sua linha editorial historicamente marcada por diretrizes politizadas, declaradamente antiimperialistas e antineoliberais.

Palavras-chave: Le Monde Diplomatique. Intelectuais. Imprensa.

\begin{abstract}
Anchored in the history of intellectuals, the political history and the history of present time, this article analyses the development of Le Monde Diplomatique's international editions, highlighting the role played by journalists and intellectuals in the definition of its editorial guideline. Founded in 1954, in Paris, by Hubert Beuve-Méry, Le Monde Diplomatique had its ideas spread across several countries - in February 2013, the magazine had more then 40 international editions (printed or only digital), an unique case in the international press. Throughout time, Le Monde Diplomatique had its style marked by politicized editorial guidelines, professedly anti-imperialist and anti-neoliberal.
\end{abstract}

Key words: Le Monde Diplomatique. Intellectuals. Press.

\section{Resumen}

Apoyado en la historia de los intelectuales, la historia política y la historia del tiempo presente, este artigo analisa el desarollo de las ediciones internacionales de Le Monde Diplomatique, destacando la función de los periodistas y intelectuales en la definición de su línea editorial. Fundado en mayo de 1954, en París, por Hubert Beuve-Méry, Le Monde 
Diplomatique asistió a la propagación de sus ideas por varios países - en febrero de 2013, la revista tenía más de 40 ediciones internacionales (impresas o estrictamente electrónicas), un fenómeno único en la prensa mundial. A lo largo de su trayectoria, Le Monde Diplomatique fue marcado por una línea editorial politizada, abiertamente antiimperialista y antineoliberal.

Palabras clave: Le Monde Diplomatique. Intelectuales. Prensa.

\section{INTRODUÇÃO}

Idealizado como suplemento diplomático do diário francês Le Monde na década de 1950, Le Monde Diplomatique ${ }^{1}$ se tornou uma prestigiada revista de política internacional de cerca de 40 páginas, nos melhores tempos somando de 2,4 milhões de exemplares no mundo todo. A partir da década de 1990, Le Monde Diplomatique firmou suas diretrizes políticas declaradamente antiimperialistas e antineoliberais - e seu estilo, com artigos assinados por intelectuais e por jornalistas de diversas nacionalidades. $\mathrm{Na}$ esteira do movimento altermundialista $^{2}$, teve suas ideias críticas contra o "pensamento único" se alastrarem mundo afora, impulsionadas sob a direção do sociólogo espanhol Ignacio Ramonet - às vésperas do $60^{\circ}$ aniversário, o periódico tinha mais de 40 edições internacionais, em 28 idiomas.

Nestas breves páginas, pretendo destrinchar o processo de internacionalização das ideias de Le Monde Diplomatique, considerado um fenômeno único na imprensa contemporânea, oscilando entre uma revista de atualidades e uma revue acadêmica, com artigos e ensaios longos, marcados por muitas notas, cronologias, dossiês, glossários, índices e referências bibliográficas. A partir de textos elaborados, assinados por escritores e editores especializados, Le Monde Diplomatique quer ultrapassar os almanaques de atualidades e as antologias efêmeras do cotidiano.

\footnotetext{
${ }^{1}$ Neste estudo, Le Monde Diplomatique encontra referência nas expressões "revista" ou "magazine" por duas razões. Primeiro, para evitar a referência a Le Monde Diplomatique como um "jornal", a fim de contornar possíveis confusões com o diário Le Monde, que é passim mencionado para narrar a trajetória, até certo ponto cruzada, das duas publicações. Segundo, a periodicidade mensal, o estilo e a linha editorial diferenciada, mais dedicada à análise e menos à "notícia", afastam Le Monde Diplomatique do perfil de um jornal nos moldes convencionais da imprensa. Entretanto, mínimas vezes Le Monde Diplomatique é citado, por outrem, como um "jornal".

${ }^{2} \mathrm{O}$ movimento altermundialista se contrapõe ao capitalismo neoliberal, consolidando-se nas manifestações durante as reuniões internacionais das principais instituições financeiras, como nos protestos de Seattle em novembro de 1999. Trata-se de um movimento contra a globalização marcadamente neoliberal, tendo como auge a realização do primeiro Fórum Social Mundial em Porto Alegre, em janeiro de 2001. Ancorada no lema "outro mundo é possível", a expressão "altermundialismo" (do francês altermondialisme) foi idealizada a partir do movimento ATTAC, vinculado ao Le Monde Diplomatique francês.
} 
Nas suas páginas escreveram importantes intelectuais contemporâneos, de diversas áreas e diferentes nacionalidades, como Edward Said (1935-2003), Eric Hobsbawm (19172012), Florestan Fernandes (1920-1995), Pierre Bourdieu (1930-2002), Tony Judt (19482010), entre muitos outros. Firmou-se nessas rubricas e nessas ideias a marca da revista, que almeja oferecer uma visão alternativa, uma mirada crítica dos acontecimentos atuais, um ponto de vista singular, uma perspectiva atilada do jogo das relações internacionais, um outro olhar ou, na expressão preferida pelos editores franceses, uma manière de voir. Assim, Le Monde Diplomatique quis se firmar como uma revista internacional realizado na França, muito mais que um magazine francês simplesmente vendido no exterior (VIDAL, 2006).

Diferentes momentos marcaram a propagação de Le Monde Diplomatique ao redor do mundo. No artigo "L'Internationale du Diplo", o jornalista Dominique Vidal revisita a trajetória que culminaria em 65 edições internacionais (34 impressas, 31 eletrônicas) em 2006, com as estreias da edição húngara em novembro e das edições finlandesa e kuaitiana em dezembro.

Entretanto, Vidal inicia sua narrativa confrontando exemplos na imprensa internacional: à época, a revista americana Newsweek teria 4 edições internacionais; o jornal The International Herald Tribune, vinculado ao americano The New York Times, 9; a revista francesa Elle, 15; Le Monde Diplomatique, 65, presentes em 25 idiomas além do francês. Enquanto as outras publicações contam com estratégias mercadológicas e campanhas publicitárias, a gazeta francesa, nas palavras do editor, contaria principalmente com o "sonho" de um outro mundo possível (VIDAL, 2006, p. 27). Le Monde Diplomatique pretenderia assim oferecer outro asset a seus leitores mundo afora: as ideias.

Na década de 1970, Portugal e Grécia foram os primeiros países a lançar edições da revista, num contexto marcado pela derrocada de suas ditaduras e pelo processo de redemocratização nesses países. Foram as primeiras, historicamente, a difundir as análises de Le Monde Diplomatique sobre política internacional.

Além das fronteiras europeias, Le Monde Diplomatique consolidou novas tentativas durante a década de 1980, com edições publicadas em espanhol. A primeira, no México, em janeiro de 1979, com 36 páginas de traduções francesas e 4 páginas especialmente dedicadas à América Latina, sob direção de José Maris Ruines Aldunate, com um comitê composto por Gonzalo Arroyo, Odile-Guilpain, Pedro Vuskovic e Rolando Weismann, encerrada após o assassinato do editor Yvan Menéndez em 5 de novembro de 1986. 
A intrincada história das diferentes edições mexicanas merece um parêntesis: Yvan Menéndez foi encontrado amordaçado em seu carro - o $359^{\circ}$ jornalista assassinado na América Latina desde 1970 (JULIEN, 1986). Antes de Menéndez, uma outra edição do Monde Diplomatique circulou no país, sob a responsabilidade de Luis Javier Solana e Federico Fasano - uma versão pirate que, lembrou Claude Julien, acumulava graves de erros na tradução do francês ao espanhol, títulos errôneos e contradições inadmissíveis, a tal ponto que a edição foi encerrada em julho de 1986.

Tempos depois, outra edição foi fundada no México. Em 23 de outubro 1998, porém, outro editor foi assassinado, também encontrado estrangulado em seu carro: o jornalista mexicano Claudio Cortés García, que também escrevia para a revista La Crisis (RAMONET, 1998). Uma década depois, mais uma tentativa: estreou a 5 de setembro de 2008 a Ediciones LeMondeDiplomex, liderada pelo jornalista francês Jean-François Boyer, com 44 páginas (31 de traduções francesas, 8 de matérias mexicanas e 5 de publicidade), junto ao diário $L a$ Jornada. Tampouco durou, mas por questões financeiras.

De volta à década de 1980, outras tentativas de edições em espanhol se dariam em Buenos Aires e depois em Madri. De Buenos Aires e Ciudad de México, Claude Julien à época via "duas capitais que jogam [jogavam] um papel essencial no difícil encaminhamento de toda a América Latina a uma democracia forte o bastante para resistir aos golpes de Estado e tentações ditatoriais, aos desastres econômicos agravados por regimes militares, às vontades imperiais de grandes potências" (JULIEN, 1986, p. 1). Entretanto, ainda eram tentativas iniciais, que não duraram por muito tempo. Logo viria uma versão trimestral em árabe, realizada entre Túnis entre 1987 e 1998, depois transferida a Beirute. Foram todas, vale destacar novamente, iniciativas muito efêmeras.

A segunda onda de internacionalização se iniciou na década de 1990, mais ampla e mais duradoura. Foram iniciadas as duas primeiras grandes edições internacionais do Monde Diplomatique: uma em alemão, publicada como suplemento do berlinense Die Tageszeitung ${ }^{3}$; outra em italiano, publicada como suplemento no romano Il Manifesto. Em 1999, o britânico Guardian Weekly passou a publicar mensalmente 16 páginas traduzidas. ${ }^{4}$ Ainda nessa época, Le Monde Diplomatique se firmaria em Buenos Aires (Capital Intelectual) e em Madri (L-

\footnotetext{
${ }^{3}$ Por tempo indeterminado, a edição alemã também foi publicada na revista Die WochenZeitung, de Zurique. Cf. LE MONDE DIPLOMATIQUE, maio de 1995, p. 2.

${ }^{4}$ Segundo Flavie Holzinger, a primeira iniciativa inglesa aconteceu em fevereiro de 1997, com uma versão web. Em setembro de 1998, tornou-se suplemento impresso no Guardian Weekly, dirigido por Wendy Kristianasen (HOLZINGER, 2013, p. 65).
} 
Press, depois Cybermonde) ${ }^{5}$, passando a ser traduzido também em português (com a editora progressista Campo Comunicação) e em grego (com o diário Eleftherotypia).

A conquista da independência editorial e financeira de Le Monde Diplomatique diante do Le Monde propiciou uma aceleração para o surgimento de novas edições internacionais. Em 1996, eram apenas 5 edições internacionais impressas, com uma tiragem total de 500 mil exemplares. Em 1999, 10 edições. Em 2000, 13 edições impressas - e aí cruzaram a marca de 1 milhão de exemplares. Em 2001, 16 edições impressas. Em 2003, 23 edições impressas. Em fins de 2004, 25 edições impressas, totalizando uma tiragem de 1,5 milhão de exemplares. Em 2006, 34 edições impressas incluindo a francesa. Entretanto, na contracorrente dessa expansão, muitos países perderam suas edições por falta de recursos financeiros, como Áustria, Líbano, México, Turquia e Venezuela. Apesar de não contarem mais com as páginas impressas, muitos países mantiveram edições apenas eletrônicas: das rotativas ao ciberespaço, Le Monde Diplomatique somava 31 edições em 2006.

Outros fatores se destacam na aceleração das edições internacionais, principalmente condições técnicas e diretrizes editoriais, ambas alavancadas por uma ferramenta: a internet. Por um lado, a internet permitiu catalisar o desenvolvimento das edições internacionais por oferecer condições primeiramente técnicas para transmitir os artigos franceses às suas filiais, a tempo de serem traduzidos e publicados com apenas dias (e não mais meses) de diferença da matriz francesa. Na mesma linha, permitiu o surgimento de edições estritamente eletrônicas.

Por outro, fora das páginas e fora das redações, a internet também começava a engendrar outras articulações, que derivariam nos primeiros movimentos internacionais descentralizados, por exemplo, dos protestos de Seattle e de Gênova - que, dentro das redações do Monde Diplomatique, engatilharia propostas para outras edições internacionais, interessadas e atraídas pela dimensão do altermundialismo na década de 2000 . No fim de 2010, a expansão atingiu certo equilíbrio, dedicando 83 mil euros a estrear ou a manter

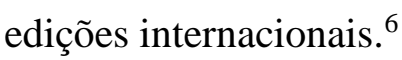

Além da vocação internacional, a revista foi difundida no exterior desde seus primeiros tempos "diplomáticos". Nas décadas de 1950 e 1960, era encaminhada às

\footnotetext{
5 Inaugurada em 1995 e inicialmente dirigida por Antonio Albiñana na editora L-Press de Madri, a versão espanhola migrou para as Ediciones Cybermonde, de Valendia, com o diretor Ferran Montesa, em 2000. Desde 2008, Ignacio Ramonet, jubilado da matriz francesa, se tornou diretor da edição espanhola (RABADÁN, 2009, p. 284-285, p. 385). A filial espanhola, vale dizer, pode ser considerada a partir daí uma das mais independentes editorialmente entre as edições internacionais: é a única que não traduz obrigatoriamente o editorial do mês de Serge Halimi da versão francesa; quem assina o editorial é Ignacio Ramonet (HOLZINGER, 2013, p. 57).

${ }^{6}$ Informação presente na tese de Flavie Holzinger, citando a newsletter de La correspondance de la presse de 7 de outubro de 2010. Cf. HOLZINGER, 2013, p. 53.
} 
embaixadas francesas noutros países. Em 1981, já sob Claude Julien, o número de exemplares encaminhados a outros países correspondia a quase 50\% da difusão. Em 2010, além das edições internacionais, Le Monde Diplomatique dedicava 22\% de sua impressão francesa ao exterior. E, em 2011, mais uma vez, além das edições internacionais, a versão francesa da revista estava presente em 92 países - apesar de escalas radicalmente diferentes, por exemplo, com meros 5 exemplares encaminhados a Gana, 10 para Guiné, 20 para a Nigéria, 1.600 para a Argélia e quase 3.000 para o Canadá (HOLZINGER, 2013, p. 36).

Três eixos estratégicos de expansão marcaram Le Monde Diplomatique ao longo do tempo: edições europeias (tendo como principais polos a alemã e a italiana), edições árabes (como a egípcia) e edições latino-americanas (como a argentina) (RABADÁN, 2009).

\title{
2 À FRANCESA
}

Apesar da notável expansão de Le Monde Diplomatique em âmbito mundial, é interessante notar que esse movimento se fez, por assim dizer, à francesa. A concepção da maioria das edições internacionais se deu timidamente, sem que Paris simbolizasse seu centro irradiador, pois o desejo de contar com uma tradução ou uma edição própria de Le Monde Diplomatique partiu da iniciativa dos próprios jornalistas e intelectuais mundo afora. Por isso, a matriz francesa desconsidera absolutamente a possibilidade de que esta internacionalização se traduza, na expressão de Dominique Vidal, num “império da imprensa mundial":

\begin{abstract}
Nem imaginamos que isto represente um império da imprensa mundial! A maior parte destas edições nasce da forte motivação de um pequeno grupo de homens e - mais frequentemente - de mulheres que não contam o tempo que dedicam a esta causa e trabalham com recursos reduzidos. Tanto é assim que o equilíbrio de diversas delas permanece frágil... Além disso, a criação da maior parte das edições estrangeiras do Le Monde Diplomatique não resultou de uma prospecção realizada a partir de Paris. Quase todos os parceiros tiveram, eles próprios, a iniciativa. Estão entre os herdeiros do maio de 68 espalhados pelo mundo, que pertencem ao movimento altermundialista ou representam, simplesmente, órgãos de imprensa social que querem cobrir melhor as realidades internacionais, todos desejosos, sobretudo, de contribuir para a difusão do Diplô, veículo que julgam sério, documentado e crítico (VIDAL, 2006, p. 27).
\end{abstract}

Fisgo desse trecho três expressões-chaves para compreender a última onda de internacionalização de Le Monde Diplomatique: os herdeiros do Maio de 1968, o boom movimento altermundialista e o selo fixado à revista como "documentado e crítico". 
Três expressões que descortinam diferentes interpretações. Das memórias do maio francês de 1968, época do Quartier Latin QG para "mais intelectuais por metro quadrado que qualquer outro canto do mundo", como escreveu o historiador Eric Hobsbawm (2013, p. 235236), outorgou-se à rebeldia estudantil, de matiz romântica revolucionária, diversos simbolismos, impressões e interpretações. Nas palavras do sociólogo Michael Löwy:

\begin{abstract}
Maio de 1968 não foi uma revolução, mas uma imensa onda de contestação social, cultural e política, sustentada em suas expressões mais radicais por uma aspiração revolucionária. Seu imaginário se alimentava de revoluções do passado e do presente - desde a Comuna de Paris até as revoluções vietnamita e cubana; trata-se, porém, de um evento inovador, com características originais. Os gestos herdados do passado, como a construção de barricadas com paralelepípedos que passam de mão em mão numa cadeia solidária, não têm a mesma função: são atos simbólicos. Não há fuzis ou granadas, e menos ainda metralhadoras ou canhões. A violência é controlada e limita-se ao arremesso de pedras e de paralelepípedos, ao qual respondem - do lado das "forças da ordem" - com o cassetete e o gás lacrimogênio. Às vezes os jovens lançam coquetéis molotov, que servem sobretudo para incendiar os carros - encarnação material da alienação mercantil - ou as próprias barricadas, a fim de impedir o avanço da polícia. O brilho dos incêndios nas ruas de Paris iluminou a imaginação social das últimas décadas, não só na França, mas um pouco em todo o mundo (LÖWY, 2009, p. 521-522)
\end{abstract}

Nas próprias páginas de Le Monde Diplomatique, nas revisões históricas a 40 anos do Maio de 1968, o politólogo Bernard Lacroix, autor de L'utopie communautaire. Mai 68, histoire sociale d'une revolte (2006), relembrou o repertório de agitações heterogêneas da época - manifestações, ocupações, marchas, sequestros, enfrentamento contra as forças da ordem - que, visto em retrospectiva, a ideia de contracultura amalgamou. Por diferentes ângulos, foi caracterizado como um complô, como uma crise mundial da juventude, como um conflito geracional, como uma crise da universidade, um confronto de classes, uma revolta, uma crise da política interna e/ou internacional.

Ao invocar o ativismo altermundialista, Dominique Vidal ainda abre outros filões de interpretações - nebuloso, o movimento recebeu diversas designações: altermundialismo, anti-globalização, movimento civil mundial, movimento da justiça global, movimento de resistência global, movimento social internacional, "movimento dos movimentos" e assim por diante. Fluidez presente ainda nas controvérsias sobre seu momento inspirador: antes de desembocar nas manifestações de Seattle (1999) e Porto Alegre (2001), a fonte estaria entre a Eco-92 no Rio, o brotar da Via Campesina no maio belga de 1993, o levante zapatista de Chiapas de 1994, entre outros (AGRIKOLIANSKY, GOBILLE, 2011, p. 140). 
$\mathrm{Na}$ esquerda francesa da época, diversas filiações, entre tradições militantes e correntes ideológicas antigas, afluíram à nebulosa do altermundialismo: esquerdas pós-maio de 1968, entre esquerda marxista, anarquismo revisitado, mobilizações campesinas, movimentos católicos de solidariedade internacional, movimentos a favor do Terceiro Mundo, movimentos dos san-papiers, dos sans logis e sans emploi, sindicalismo e mídia alternativa, como Le Monde Diplomatique (AGRIKOLIANSKY, FILLIEULE, MAYER, 2005, p. 12). Não por acaso, vale lembrar, Le Monde Diplomatique desde a década de 1970 se solidarizou com o terceiro-mundismo ${ }^{7}$ e os movimentos de descolonização.

Um detalhe não explorado no editorial: nas décadas de 1960 e 1970, diante da ascensão das ditaduras militares, muitos intelectuais latino-americanos buscaram refúgio na França, época em que Paris se tornou um tipo de "capital" do exílio. ${ }^{8}$ Enquanto produtora de ideias e propagadora de ideologias, a França simbolizou, para os intelectuais latinoamericanos, inspirados na cultura francesa, uma vanguarda política até meados da década de 1970. Reivindicada pela esquerda francesa na década de 1960, a ideologia terceiro-mundista tentou preencher o vazio deixado pelo desaparecimento dos confrontos de classes no território europeu - e assim, em busca de novos ideais revolucionários, muitos militantes políticos voltaram os olhares aos focos latino-americanos, primeiro a Cuba, depois ao Chile.

Enquanto cá miravam certas mentes europeias, mentes latino-americanas lá imigravam, florescendo e proliferando relações com a esquerda francesa da época, escrevendo para revistas importantes como Les Temps Modernes, La Pensée e Cahiers de l'Amérique Latine, compondo temporariamente quadros de prestigiadas universidades como Paris $\mathrm{X}$ Nanterre, Paris VIII - Vincennes e Paris III - Sorbonne Nouvelle (RODRIGUES, 2008). Apenas para citar dois exemplos de refugiados latino-americanos: uma vez exilados na capital francesa, o jornalista argentino Carlos Alberto Gabetta ${ }^{9}$ e o historiador brasileiro Luiz Felipe

\footnotetext{
${ }^{7}$ Nos Mitos revolucionários do Terceiro Mundo, escritos entre 1972 e 1975, Gérard Chaliand lembra a "euforia" terceiro-mundista florescente no fim da década de 1950, durante a Guerra da Argélia - e logo reforçada pela radicalização da Revolução Cubana. Na Europa, a obra de Frantz Fanon, especialmente Les damnés de la terre, inspirou a corrente. Na França, o gatilho foi a Guerra da Argélia; nos Estados Unidos, a Guerra do Vietnã. Tal "euforia" marcou a década de 1960, desenvolvendo-se no contexto da descolonização e do surgimento de movimentos revolucionários armados na Ásia, na África e na América Latina (CHALIAND, 1977, p. 8).

${ }^{8} \mathrm{Um}$ dos maiores exílios intelectuais do século XX se deu nessa época. O destino primeiro de muitos intelectuais latino-americanos foi o Chile mas, após o golpe de Augusto Pinochet, a parada final se tornou a França.

9 Após o golpe de 1976, o jornalista rosarino Carlos Alberto Gabetta se exilou em Paris, onde conheceu Bernard Cassen, depois Claude Julien e Ignacio Ramonet. Anos mais tarde, tentaria realizar Le Monde Diplomatique em Barcelona e, finalmente, em Buenos Aires.
} 
de Alencastro escreveram sobre as ditaduras de seus países para Le Monde Diplomatique Alencastro assinava com o pseudônimo Julia Juruna. ${ }^{10}$

Se, portanto, para Dominique Vidal, o desejo de ter uma edição própria da revista partiria dos "herdeiros do Maio de 1968" espalhados pelo mundo, desejosos, principalmente, por participar da difusão de suas ideias - tal sentimento se justificaria pelo fato de que muitos jornalistas, intelectuais e militantes de outras nacionalidades e outras trajetórias compartilhem sua visão de mundo. Uma visão singular, uma manière de voir, como frisado noutras passagens. Assim, no amplo espectro do simbolismo do maio francês e das difusas diretrizes do altermundialismo, Le Monde Diplomatique seria visto como “documentado e crítico" por ativistas, estudantes, intelectuais, jornalistas e políticos de outros países. Na visão de Vidal, o principal momento para a internacionalização de Le Monde Diplomatique coincide com o desenvolvimento do movimento altermundialista, que "deu a ideia a certos jornais, jornalistas e intelectuais de criar sua própria edição". ${ }^{11}$

Nascido em 18 de junho de 1950, em Paris, Dominique Vidal iniciou a carreira na imprensa comunista francesa, na revista France Nouvelle, depois France Nouvelle: Révolution. Na manhã de 6 de outubro de 2014, num café na Place d'Italie, a poucas quadras da redação do Monde Diplomatique, o jornalista lembrou os descaminhos que o levaram até lá. A partir de 1983 principalmente, Vidal teve conflitos com o Partido Comunista Francês $(\mathrm{PCF})$, pois discordava de seus posicionamentos em questões internacionais, sobretudo a respeito dos países comunistas do Leste.

Assim, em 1986, figurou entre 7 dos 20 jornalistas demitidos do Révolution, o que os situaram numa dupla "lista negra": por um lado, muitas mídias não queriam jornalistas vindos da imprensa comunista; por outro, passaram a ser consideros inimigos do PCF, logo a imprensa próxima, alinhada ou aliada, tampouco os queriam. Vidal passou dois anos desempregado. Por volta de 1987, começou a colaborar com Le Monde Diplomatique. Tempos depois, sensível à sua situação, o jornalista Nöel Copin (1929-2007), diretor do diário católico La Croix, contratou Vidal como secretário de redação.

Depois de La Croix, Vidal foi sub-diretor do Centre de Formation des Journalistes, uma das principais escolas francesas de jornalismo, onde era responsável pela editoria

\footnotetext{
10 O historiador e cientista político catarinense Luiz Felipe de Alencastro foi recebido com outros expatriados na casa da socióloga Violeta Arraes, irmã de Miguel Arraes, governador de Pernambuco deposto pelos militares em $1^{\circ}$ de abril de 1964. Exilado a partir de 1966 em Paris, a quilômetros de distância do Brasil, Alencastro, como muitos perseguidos políticos, preferiu se prevenir, escolhendo um pseudônimo para assinar seus artigos no exterior. Assim, Julia Juruna escreveu diversas vezes no Monde Diplomatique.

${ }^{11}$ Dominique Vidal em entrevista à autora, no dia 6 de outubro de 2014.
} 
internacional. Criou cursos de pós-graduação de jornalismo no exterior - países como Camboja, Líbano e Tunísia. Nessa época, Ignacio Ramonet o convidou para integrar a equipe de Le Monde Diplomatique, onde ficou entre 1995 e 2010, quando se aposentou.

No Monde Diplomatique, ademais de sua expertise em questões relacionadas ao Oriente Médio, o principal papel de Dominique Vidal era coordenar as edições internacionais - uma aposta que, diz, demorou para darem importância. Nos primeiros tempos, com apenas três edições internacionais (as versões alemã, italiana e mexicana), Vidal precisava enviar a edição francesa impressa, via correio, para os parceiros no exterior. Isto é, à espera da edição francesa impressa para traduzir todos os artigos, os parceiros só publicavam as versões nos seus países com cerca de 30 dias de atraso.

O editor tentou desenvolver outro modelo, mais veloz: passou a encaminhar os arquivos franceses assim que finalizados, artigo por artigo, reduzindo o atraso para 7 ou 10 dias após a publicação do número parisiense. Vidal também viajou para diversos países, para conhecer, ajudar e conversar com possíveis parceiros, muitos com equipes diminutas e recursos financeiros limitados.

Dentro do próprio Le Monde Diplomatique, a ideia de ter edições internacionais passou a ser respeitada, legitimada e estimulada a partir de fins da década de 1990, mas principalmente nos anos 2000, quando notaram a janela aberta para a difusão de suas ideias. Interessa, portanto, à matriz francesa a difusão de suas ideias mundo afora. Interessa, por sua vez, às edições internacionais o acesso a artigos "únicos" sobre política e relações internacionais.

Assim foi reiterado o perfil internacional de Le Monde Diplomatique, quer dizer, além de suas páginas desde a década de 1950 já dedicadas à política internacional, desde a década de 1970 assinadas por intelectuais e jornalistas de diversas nacionalidades, agora as articulações de seus intelectuais com outras redações e núcleos jornalísticos permitiram imprimir mais uma vez um certo cosmopolitismo na identidade da revista.

Em maio de 2004, para marcar o $50^{\circ}$ aniversário da "matriz" - a edição francesa fundada em 1954 -, as edições internacionais se reuniram no Palais de Sports, na Porte de Versailles, no $15^{\circ}$ arrondissement parisiense.

Paris foi uma festa: reuniram-se mais de 5.000 convidados, entre escritores, ensaístas, filósofos, jornalistas, militantes, músicos, sindicalistas. Nas palavras de Vidal, o reencontro dos intelectuais foi como um eco dos grandes movimentos para a paz com o pós-guerra - ou como os seminários antifascistas da década de 1930. Entre brindes, discursos e, 
principalmente, reflexões sobre o mundo originado da Guerra Fria - e as melhores vias para transformá-lo. Os editores e colaboradores revisaram a situação política internacional e definiram diretrizes para as próximas iniciativas de Le Monde Diplomatique.

Entre as diversas vozes de resistência reverberadas no encontro, intelectuais de diversos campos tomaram a palavra. Na literatura, nomes como o uruguaio Eduardo Galeano (1940-2015), a canadense Naomi Klein e o Nobel português José Saramago (1922-2010). Na política, o porta-voz da Via Campesina José Bové, o dirigente do MST João Pedro Stédile e o boliviano Evo Morales, antes de conquistar a presidência de seu país. Entre as vozes femininas e feministas, a socióloga francesa Christine Delphy, a ex-ministra malinesa Aminata Dramane Traoré e a bengalesa Irene Khan, da Anistia Internacional.

Além de Antonio Negri, Etienne Balibar, Jacques Derrida (1930-2004) e Régis Debray, dois outros intelectuais tiveram suas vozes reverberadas, mas transmitidas virtualmente: uma vídeo-conferência do filósofo americano Noam Chomsky e um vídeo in memoriam do intelectual palestino Edward Said (1935-2003). Diretor do Monde Diplomatique à época, o sociólogo galego Ignacio Ramonet, por sua vez, dedicou seu discurso a Pierre Bourdieu (1930-2002).

O filósofo Jacques Derrida, “amigo fiel” de Le Monde Diplomatique, homenageou a revista, que considerava a aventura e a ambição jornalística mais notáveis dos últimos 50 anos - e, ainda nas suas palavras, não só em Paris, na França e na Europa. O discurso na festa "diplomática" no dia 8 de maio de 2004 foi lembrado não muito tempo depois, por ocasião de sua morte, no dia 9 de outubro de 2004. Nesta, uma de suas últimas intervenções, dissera:

Nos últimos 50 anos transcorridos, inegável e irreversivelmente transcorridos, Le Monde Diplomatique representou, para mim, a honra e a coragem do que foi, através de uma informação objetiva e rigorosa, frequentemente indetectável noutros lados, algo mais que um modelo jornalístico herdeiro do melhor passado; simultaneamente, no mesmo movimento, significou um convite e um estímulo para o futuro (DERRIDA, 2004, p. 36).

Derrida almejava ler um dia uma história analítica do cinquentenário Le Monde Diplomatique - que, julgava, seria uma campanha imensa para os historiadores do futuro. Recompor tal história requereria lembrar os fundamentos do Monde Diplomatique dos tempos de Beuve-Méry, e seus movimentos ao lado do tempo:

E isso certamente através de múltiplos movimentos, com reviravoltas às vezes audazes, inclusive perigosas, ou expostas à própria discussão, que, 
felizmente, ainda pode ocorrer entre os amigos do diário. Esta fidelidade se manteve através de todas as equipes e suas sucessivas direções. O que mudou, quem poderia negar, é o mundo, não o jornal, mas seu grande homônimo, seu referente desordenado, o próprio mundo. $\mathrm{O}$ mundo foi abalado e rachado e reconstruído por todos os tipos de terremotos. Os conceitos e as formas do que ainda ontem se dizia o "mundo da diplomacia" foi radicalmente alterado, mas Le Monde Diplomatique não mudou, pelo menos em espírito, em seus princípios fundamentais, mas se altermundializou (DERRIDA, 2004, p. 36-37).

Por dez horas, o Palais de Sports se tornou palco para diversas intervenções intelectuais, sintonizadas com manifestações musicais e artísticas, ecléticas do jazz ao rap, com Bernard Lubat, Gnawa Diffusion, Gilles Non, La Rumeur, Manu Dibango, Paco Ibáñez, entre outros. Fim de festa, quase à meia-noite em Paris.

Paris, aliás, é o eixo desses círculos concêntricos intelectuais internacionais - muito embora recuse tal centralidade, o que se vê na expressão de Dominique Vidal recusando Le Monde Diplomatique como um "império da imprensa mundial”, os laços de família entre Le Monde Diplomatique e suas filiais internacionais não pode ser caracterizado por relações entre edições “irmãs" ou "primas", isto é, por relações horizontais no réseau. Há certa hierarquia, como veremos, que talvez mereça como metáfora familiar mais oportuna as relações entre uma mãe, matriz parisiense e seus filhos espalhados pelo mundo.

E os filhos pródigos à casa tornam. Le Monde Diplomatique realiza reuniões anuais com os editores das edições internacionais - mas, por questões financeiras, nem todos comparecem sempre. As reuniões são realizadas em diferentes cidades, como Paris, Londres, Bruxelas e outras capitais europeias, por volta de junho. Ali os intelectuais e jornalistas discutem as linhas do Diplô no mundo, o que passou e o que virá.

\section{DIRETRIZES}

De caderno especial destinado às chancelarias e consulados parisienses, Le Monde Diplomatique se transformou a partir da direção de Claude Julien, que impulsionou uma orientação mais marcada e mais marcante, no sentido do terceiro-mundismo diante de uma ordem bipolarizada. "Tornou-se um jornal engajado", diz Vidal. ${ }^{12}$ A direção de Ignacio Ramonet seguiu e acentuou essa orientação - tornando-se, aos olhos do jornalista, ainda mais engajado, principalmente no sentido do altermundialismo. Para Vidal, Serge Halimi preservou as diretrizes editoriais de Julien e Ramonet, mas afrouxou os laços com o

12 Dominique Vidal em entrevista à autora, no dia 6 de outubro de 2014, grifo meu. 
movimento altermundialista, isto é, Halimi e Le Monde Diplomatique, sem serem hostis às propostas altermundialistas, agora considerariam que não é papel da imprensa estar diretamente ligada a um movimento.

É importante lembrar as linhas-mestras de Le Monde Diplomatique para compreender como suas diretrizes se ajustam às edições internacionais. Se a revista se posiciona, orgulhosamente vale dizer, com determinada personalidade, identidade e caráter, é preciso compreender até que ponto se mostra flexível para dialogar com suas filiais. No âmbito pragmático, Vidal conta que tentou incutir a ideia de flexibilidade a respeito das edições internacionais no Monde Diplomatique - mas foi difícil, principalmente para as direções aceitarem os diferentes perfis dos parceiros: por exemplo, o comunista italiano Il Manifesto e o mainstream grego Eleftherotypia.

A fim de equilibrar identidade e flexibilidade, a matriz se pautou por um critério jornalístico, não político: se Le Monde Diplomatique for impressa como suplemento especial dentro de um diário, a edição deve se limitar a publicar apenas artigos de Le Monde Diplomatique, pois os outros artigos, de outros estilos, linhas editoriais e principalmente políticas, já estarão contemplados nos cadernos cotidianos do diário; se, por outro lado, Le Monde Diplomatique for idealizado e realizado por uma editora ou um círculo de intelectuais e jornalistas, a matriz francesa deve aceitar que a edição inclua artigos e editoriais próprios, sobretudo relacionados à realidade do próprio país.

A partir de tais critérios, atualmente é possível observar três tipos de edições internacionais de Le Monde Diplomatique. Primeiro, há versões independentes mistas, que mesclam traduções dos artigos franceses, obrigatórias por questões contratuais, e artigos próprios - por exemplo, as edições realizadas na Argentina, no Chile e no Brasil. Segundo, há versões integrais, que traduzem $100 \%$ das matérias francesas para o próprio idioma - caso das edições encartadas como suplemento noutros jornais, como na Grécia (Eleftherotypia) e na Itália (Il Manifesto). Terceiro, edições financiadas pela matriz francesa do Monde Diplomatique, como a edição espanhola e a versão inglesa. Inicialmente, a redação francesa e The Guardian mantinham juntos a edição, mas o berliner britânico quis interromper a parceria - a edição se mantém atualmente, mas sustentada apenas pelo bureau francês.

No campo das traduções, duas edições se destacaram nos últimos tempos: Berlim e Buenos Aires. A edição alemã traduz todos os artigos franceses, repassando-os às edições de Suíça e Luxemburgo, também à efêmera edição da Áustria. A edição argentina, por sua vez, repassa suas traduções para Madri e América Latina. 
Ainda a respeito da busca de equilíbrio entre identidade e flexibilidade, Le Monde Diplomatique estipulou um acordo contratual com as edições internacionais: oficialmente, $70 \%$ dos artigos franceses devem ser traduzidos e impressos nas edições internacionais independentes, que podem escolher como preencher os demais $30 \%$, com artigos e editoriais próprios. Entretanto, essa simples afirmação abriga três imprecisões. Por um lado, ao entrevistar diferentes fontes das edições na Argentina, no Brasil e no Chile, a resposta sobre as proporções variou entre $70 \%$ - 30\%, $60 \%$ - 40\% e 50\% - 50\%, o que já mostra os contornos variáveis da regra.

Por outro lado, considerando os $70 \%$ oficiais, os editores franceses dizem que a regra não é tão rígida, não é totalmente matemática, pois não vão medir à régua as impressões de suas filiais, tolerando as edições a extra-oficialmente extrapolar o conteúdo próprio. Por fim, Vidal cravou $70 \%-30 \%{ }^{13}$, mas Anne-Cécile Robert afirma $75 \%-25 \% .^{14}$

Em fins de 2010, Dominique Vidal se aposentou e se despediu do Monde Diplomatique. Anne-Cécile Robert assumiu a direção das edições internacionais. Conversei com Dominique Vidal no Café de France, esquina da Place d'Italie com o Boulevard Auguste Blanqui, um encontro amigável, entre cafés expressos e tilintares de talheres de garçons malhumorados, e quase informal ou, na expressão do editor, sem langue de bois [conversa fiada]. Encontrei Anne-Cécile Robert, por sua vez, por duas vezes: nos dias 4 de fevereiro de 2013 e 14 de outubro de 2014, entre livros empilhados e estantes repletas de arquivos coloridos do Monde Diplomatique, no predinho de tijolo à vista na arborizada e tranquila Avenue StephenPichon, Place d'Italie.

Nos dois encontros, mais formais, a jornalista, uma das poucas representantes da ala feminina na revista, se mostrou mais "diplomática", quer dizer, mais cautelosa nas palavras e nas expressões escolhidas para responder à entrevista - o que todavia não se traduziu em falta de crítica ou de auto-crítica. Diplomaticamente marcou suas posições, algumas dissonantes das de seu antecessor.

Nascida em 28 de abril de 1967, em Paris, Anne-Cécile Robert se doutorou no Institut d'Études Européennes da Université Paris VIII. Uniu-se ao Monde Diplomatique por volta de 1998, a convite do veterano Bernard Cassen, a quem conhecera no Le Cercle Condorcet. Autora de Afriques, années zero (L'Atalante, Nantes, 2008) com Jean-Christophe Servant, e Un totalitarisme tranquille (Syllepse, 2001) com André Bellon, Robert focava mais questões

13 Dominique Vidal em entrevista à autora, no dia 6 de outubro de 2014.

14 Anne-Cécile Robert em entrevista à autora, no dia 14 de outubro de 2014. 
africanas e direito internacional. Em 2010, passou a coordenar as edições internacionais. A respeito das conversações e correspondências com editores de outros países, tanto Robert quanto Vidal destacaram uma expressão para definir a relação com as edições internacionais: família. E há dramas nas melhores famílias.

Apesar de içar Le Monde Diplomatique a um fenômeno "único" na imprensa mundial, as edições internacionais são marcadas por certa fragilidade, principalmente financeira. Um primeiro sinal é a imprecisão do número de edições internacionais, lembrando que muitas se iniciam, mas também se despedem dos quiosques muito rapidamente.

Em março de 2011, seriam 84 edições internacionais, em 27 idiomas (41 impressas, num total de 2.400.000 exemplares, e 43 eletrônicas).

Em novembro de 2006, Dominique Vidal celebrava 65 edições, em 26 idiomas, entre versões impressas e digitais. Em fevereiro de 2013, além das 47 edições, Anne-Cécile Robert indicava novas iniciativas na Croácia, no Equador e em Honduras, além de retomar uma edição antiga na Austrália. Em outubro de 2014, o total caiu para 31 edições, em 25 idiomas, entre versões impressas e digitais. Enquanto a edição croata fechava portas, a edição sérvia as abria. Estreou nesse mês ainda a edição porto-riquenha, como suplemento de oito páginas no alternativo Compartir es vivir.

Le Monde Diplomatique foi difundido na América Latina (Argentina, Bolívia, Brasil, Chile, Colômbia, México, Porto Rico, Uruguai, Venezuela), na Ásia (Coreia do Sul, China, Índia, Japão), na Europa (Alemanha, Armênia, Bulgária, Bielorrússia, Croácia, Espanha, Eslováquia, Eslovênia, Finlândia, França, Grécia, Hungria, Itália, Luxemburgo, Noruega, Polônia, Portugal, República Tcheca, Rússia, Suécia, Suíça, Turquia) e no Oriente Médio (Arábia Saudita, Curdistão, Dubai, Egito, Emirados Árabes Unidos, Iêmen, Irã, Líbia, Kuait, Palestina, Tunísia) em diferentes momentos ao longo de sua trajetória. Além do francês, do inglês e do espanhol, foi traduzido para idiomas mais "distantes" como curdo sorâni, curdo kurmandji, esperanto, farsi e finlandês, entre outros.

No entanto, é difícil precisar o número de edições internacionais pois a rede é muito fluida e às vezes frágil, assim muitas versões são repentinamente encerradas e outras vão e vêm: por exemplo, após a breve experiência de 1975, inicialmente dirigida por Snu Abecassis na editora D.Quixote, após quase quinze anos a edição portuguesa voltou em abril de 1999, assumido pela cooperativa Outro Modo.

Diante da complexa amplitude de Le Monde Diplomatique, é imprescindível considerar duas questões: uma intelectual e uma internacional. Por um lado, apesar de suas 
linhas-mestras, editoriais e políticas, Le Monde Diplomatique não pode ser visto como um caderno simples e homogêneo. Há indubitavelmente diversas dimensões para a heterogeneidade intelectual da revista - as nuances dos diferentes autores, ideias, linhas, ainda que predominantemente à esquerda. Por outro lado, o caráter cosmopolita ainda oferece outro campo de tensões para as identidades presentes na revista - dentro da edição francesa, há jornalistas e intelectuais de diversos horizontes, com ideias fortes sobre diferentes países; mas fora da edição francesa, ainda há jornalistas e intelectuais dum leque muito maior, também com posições fortes sobre os próprios países.

Nesse jogo de espelhos fragmentados, marcado pela pluralidade de identidades intelectuais nesse contexto extremamente internacionalizado, é preciso considerar como uns e outros se veem refletidos. Diante do risco de esquizofrenia, quão fortes seriam as linhasmestras do Monde Diplomatique para garantir uma identidade?

Um desvio delicado aconteceu com a edição norueguesa, que publicou um artigo lançando hipóteses sobre a participação do governo norte-americano nos atentados de 11 de Setembro, na sua edição de julho de 2006. A matriz francesa discordou da "paranoia" da publicação e, na sua edição de dezembro de 2006, publicou um artigo do jornalista Alexander Cockburn (1941-2012), editor da revista CounterPunch, que criticava duramente as teorias da conspiração. Tempos depois, a filial norueguesa voltou a afrontar a matriz, publicando uma resposta a Cockburn na edição de março de 2007, de autoria do filósofo norte-americano David Ray Griffin.

Outra fragilidade é a presença tímida na Ásia e a ausência nos Estados Unidos. Ali, Le Monde Diplomatique se faz presente apenas através da edição eletrônica britânica. Apesar das discussões iniciais com as revistas The Nation e Harpers, a ideia não vingou. Dizem, segundo a editora, que os americanos não estão tão interessados no que os franceses pensam sobre relações internacionais. Por volta de 2010/2011, a matriz francesa recebeu uma proposta da revista Forbes - o que, na visão de Anne-Cécile Robert: "Quer dizer que Le Monde Diplomatique é um jornal prestigiado. É uma referência. Mesmo sendo um jornal com suas convicções, ideias, opiniões muito marcadas, é também uma referência. Disse 'não' à revista Forbes, pois seria muito complicado do ponto de vista editorial". ${ }^{15}$

Nos melhores momentos, porém, o nascimento das edições internacionais sempre é comemorado. Tanto Vidal quanto Robert dizem que, na maioria das vezes, jornalistas, intelectuais e acadêmicos leitores primeiramente de diversas nacionalidades vão bater à porta

15 Anne-Cécile Robert em entrevista à autora, no dia 14 de outubro de 2014. 
do Monde Diplomatique francês para dialogar e negociar a possibilidade de levar a revista a seus países. Logo, o pontapé inicial é muito simples, informal, casual. "É uma network, mas profissional. Muitos somos amigos, discutimos notícias, trocamos experiências. Enfim, pensamos o mundo", define Vidal. ${ }^{16}$

Palavras a respeito dos leitores do Monde Diplomatique: além dos leitores mais fieis e "ativos", reunidos na Association Les Amis du Monde Diplomatique, a revista conta com diferentes perfis de leitores. Em novembro de 1985, o estudo Sofres 30.000 mostrava que o público-alvo da revista era predominantemente masculino $(69,7 \%)$, relativamente jovem entre 25 e $34 \operatorname{anos}(31,1 \%)$ e entre 35 e 49 anos (27,5\%), com ensino superior $(67,8 \%)$, principalmente atuantes nos negócios - affaires cadres (36,7\%) e nas profissões intermediárias $(21,2 \%)$, vivendo nas áreas metropolitanas de Paris $(53,1 \%) .{ }^{17} \mathrm{Na}$ época, os leitores totalizavam 557 mil, na difusão de 52.698 exemplares (HOLZINGER, 2013, p. 41).

Por volta de outubro de 1998, outro estudo, do Conseil Sondage Analyses (CSA), mostrava informações sobre o perfil dos leitores, entre casuais e assinantes, destacando o elevado nível sócio-cultural dos leitores, $60 \%$ com bacharelado, com hábitos culturais muito fortes, entre cinema, museus e teatro, com cultura literária e livresca acima da média dos franceses. Realizado entre 2009 e 2010, um terceiro estudo, da Audipresse, mostrava certa linearidade no perfil: predominantemente masculino (55\%), mas mais velho (43\% com mais de 40 anos, $27 \%$ entre 35 e 49 anos, $15 \%$ entre 15 e 24 anos, $15 \%$ entre 25 e 24 anos), com alta escolaridade (79\% com bacharelado, entre eles $60 \%$ com pós-graduação) e maior concentração urbana, principalmente na área metropolitana de Paris (72\%) - o leitor envelheceu e se intelectualizou ainda mais.

$\mathrm{Na}$ perspectiva do historiador Nicolas Harvey, Le Monde Diplomatique difere da maioria das mídias radicais anticapitalistas francesas por seu elitismo, isto é, por seu foco nos leitores de forte capital cultural, interessados nas palavras de experts, intelectuais e jornalistas prestigiados, versando sobre temas complexos e num estilo austero (HARVEY, 2011, p. 221). Assim, em linhas gerais, entre os leitores da revista na França e no mundo, dois segmentos merecem destaque especial. De um lado, os formadores de opinião: artistas, ativistas, intelectuais, jornalistas, parlamentares, professores e dirigentes de organizações da sociedade civil, atraídos pelo debate plural sobre questões fundamentais na política nacional e pela cobertura de assuntos internacionais. De outro, o segundo segmento é formado por estudantes

\footnotetext{
${ }^{16}$ Dominique Vidal em entrevista à autora, no dia 2 de abril de 2013.

${ }^{17}$ Cf. LE MONDE DIPLOMATIQUE, novembro de 1985, p. 25.
} 
e professores universitários. Assim, diversos outros tipos de leitores ficaram fora dos estudos referidos, como intelectuais de diversas nacionalidades, interessados a ponto de querer levar o selo para seus países.

Simbolizado como "polo de resistência intelectual", Le Monde Diplomatique atrai ainda diferentes etiquetas: resistência intelectual, guerra ideológica, batalha de ideias - um vocabulário, como diz o historiador Maxime Szczepanski-Huillery, senão militar, no mínimo militante. O bureau parisiense do Monde Diplomatique divide, literalmente, espaço com outras iniciativas, mais militantes: o Observatoire Français des Médias e, desde 2007, a Association Mémoire des Luttes, idealizada por Ignacio Ramonet e Bernard Cassen. Antes abrigada na Maison de l'Amérique Latine, no Boulevard Saint-Germain, a partir de 2003, a Association Les Amis du Monde Diplomatique migrou para o mesmo endereço.

Oficialmente em maio de 1995, Les Amis foram reunidos para cumprir prioritariamente um desígnio: angariar os 10 milhões de francos necessários para a filialização do Monde Diplomatique dentro do Monde (SZCZEPANSKI-HUILLERY, 2009, p. 502). Nas palavras de Claude Julien, para contribuir, por vias materiais e intelectuais, ao desenvolvimento e à independência do Monde Diplomatique. Na crítica de SzczepanskiHuillery, porém, Les Amis atravessaram tensões entre sua proposta inicial e a vontade manifesta de uma ala considerável de leitores, desejosos de articular ações militantes - uma tensão que ficaria mais nítida em junho de 1998, no imbróglio da instituição da Association pour la Taxation des Transactions Financières et pour l'Action Cityoenne (ATTAC), movimento-laboratório liderado por Ignacio Ramonet e Bernard Cassen contra a mundialização do capital neoliberal, sintonizado com as flamejas de Chiapas (1994) e Seattle (1999), que culminaria no primeiro Fórum Social Mundial, em Porto Alegre (2001).

Pensar, portanto, como Le Monde Diplomatique foi/é "lido" implica considerar diferentes perspectivas: quem escreve, o que escreve e para quem escreve Le Monde Diplomatique. No jogo de espelhos a aproximar campos jornalísticos, intelectuais e militantes como seus autores e, ao mesmo tempo, como seus leitores, a revista impulsionou a difusão de suas ideias além das fronteiras francesas. E, nessa linha, é preciso considerar que muitos leitores, de outras nacionalidades, quiseram participar mais ativamente dessa difusão, ao propor fundar edições nos seus próprios países.

Ao receber propostas para iniciar novas edições, Anne-Cécile Robert busca informações sobre os potenciais parceiros - suas posições, seus históricos, seus backgrounds. Para a editora, o ponto principal é ter certeza de que estão de acordo nas questões editoriais e 
políticas. "E, sobre a situação financeira das outras edições, nós não somos gananciosos. Não queremos dinheiro. Queremos espalhar nossas ideias ao redor do mundo”, diz. ${ }^{18}$ Nessa linha, Le Monde Diplomatique estipula as taxas impostas às edições internacionais, referentes aos direitos autorais da edição francesa, segundo as condições financeiras de cada país.

Ao assumir o lugar de Vidal, a quem reconhece pelo trabalho excepcional, Robert buscou dar continuidade à consolidação da rede de edições internacionais, por exemplo, intermediando relações com as embaixadas e instituições culturais francesas nos países, "linkando" seus editores e procurando financiamento mediante subvention européene. Também buscou divulgar a rede, com iniciativas como uma mesa-redonda aberta sobre as edições internacionais na Université Paris VIII - Saint-Denis, em maio de 2014, na efeméride do $60^{\circ}$ aniversário de Le Monde Diplomatique, e uma mesa-redonda sobre as edições internacionais no primeiro Forum Mondial de la Langue Française em Montreal, em julho de 2012.

De tempos em tempos, a editora faz uma pilha das edições internacionais impressas, para conferir seu andamento. Nas línguas e contextos sócio-políticos fora de seu domínio, conta com a ajuda dos editores especializados e às vezes de intelectuais desses países, colaboradores do Monde Diplomatique.

Em janeiro de 2013, Robert recebeu uma mensagem de um jornalista lituano, interessado em iniciar uma edição na Lituânia - um país cujo contexto político não lhe é familiar. Primeiro pediu ajuda a um dos jornalistas do Monde Diplomatique para obter informações e, depois, conversou com o diretor do jornal, para saber se suas ideias se alinhavam, pois: "O ponto principal é ter certeza de que estamos de acordo em questões políticas. É garantir que estamos de acordo com a linha editorial". ${ }^{19}$

Diante dessas diretrizes todas, estar de acordo em questões editoriais e políticas salta como a premissa mais importante. Para Vidal, a matriz francesa do Monde Diplomatique é "indiscutivelmente anticapitalista, altermundialista, terceiro-mundista", o que o posicionariam à esquerda no espectro político, mas:

Não diria, como muitos dizem, que todas as edições de Le Monde Diplomatique são esquerdistas. Nem todas são left-wing, nem todas são mainstream. Nem todas são altermundialistas. Mas é claro que todos esses movimentos mundiais - como os anti-globalização, como mostrou o Occupy Wall Street e outros movimentos nos países árabes, na Espanha e na Rússia

18 Anne-Cécile Robert em entrevista à autora, no dia 4 de fevereiro de 2013.

19 Anne-Cécile Robert em entrevista à autora, no dia 14 de outubro de 2014. 
- se alinham e fazem sentido com Le Monde Diplomatique. Então, o ponto comum entre as edições internacionais é a visão crítica. O mais importante e essa é a chave para a história de Le Monde Diplomatique - é a crítica. Mesmo os que não concordam politicamente podem encontrar informação séria e real no Monde Diplomatique, com análises profundas e perspectiva. ${ }^{20}$

Mas, apesar dessa declaração, o editor vê as fragilidades das edições internacionais como reflexo da fragilidade da imprensa à esquerda atual:

É difícil separar a vida de Le Monde Diplomatique e a de suas edições internacionais. A fraqueza das edições internacionais é a fraqueza da imprensa de esquerda atual. É claro que estamos vivendo um tempo de muitas possibilidades, de novas possibilidades. Mas, na questão financeira, é um tempo difícil para a imprensa de esquerda. Nós tivemos boas e más experiências. Nós iniciamos e encerramos edições, muitas brevemente. Mas, em linhas gerais, podemos nos orgulhar de certas conquistas. ${ }^{21}$

Por "esquerda", Dominique Vidal compreende primeiramente uma crítica hostil à sociedade capitalista, devido a suas injustiças de diversas ordens. Logo, uma busca por alternativas, frisa no plural, ao mesmo tempo justas socialmente e respeitando a identidade social e cultural dos povos. Por fim, uma aversão às políticas imperialistas, a partir dos ideais de justiça e de igualdade. Considera, assim, a matriz francesa indiscutivelmente anticapitalista, altermundialista, terceiro-mundista - características, diz, de uma imprensa contemporânea de esquerda. $^{22}$

Para Anne-Cécile Robert, por sua vez, as edições internacionais herdariam o DNA do Monde Diplomatique francês: a crítica ao imperialismo, ao colonialismo e ao capitalismo neoliberal. Uma “questão de valores", na sua expressão.

Por "valores", a editora se refere às ideias de justiça, liberdade, solidariedade. Entretanto, a editora não gosta das expressões direita e esquerda. Essencialmente prefere ver os intelectuais de Le Monde Diplomatique como free-minders, opostos ao imperialismo e à dominação de qualquer sorte: de ricos sobre pobres, de brancos sobre negros, de homens sobre mulheres, e assim por diante. "Se isso quer dizer left-wing, então, sim, estamos à esquerda".23

Interpreta Le Monde Diplomatique como uma crítica ao imperialismo, lembrando que, nos tempos de Guerra Fria, assistiam a dois imperialismos e, assim, a revista preferiu não

\footnotetext{
${ }^{20}$ Dominique Vidal em entrevista à autora, no dia 2 de abril de 2013.

21 Dominique Vidal em entrevista à autora, no dia 2 de abril de 2013.

22 Dominique Vidal em entrevista à autora, no dia 6 de outubro de 2014.

23 Anne-Cécile Robert em entrevista à autora, no dia 4 de fevereiro de 2013.
} 
tomar partido de um imperialismo ou de outro. "Para nós", define a editora, "não se trata de tomar posição de quaisquer 'competições', mas se trata de criticar os mecanismos, as lógicas e os casos de dominação, de criticar as injustiças - e não necessariamente entrar numa guerra entre X ou Y". ${ }^{24}$ Aliás, Robert discorda do pressuposto de uma relação mais direta entre o boom de Le Monde Diplomatique e o altermundialismo - que, a seu ver, foi um acelerador, mas não foi um fator capital. Em outras palavras, defende que a revista se desdobrou em edições internacionais por mérito próprio, mas não intrinsecamente relacionado a condições contextuais como o aflorar do movimento no mundo e na França.

Todavia, entre uma revista francesa difundida no exterior e uma revista internacional nascida na França, Anne-Cécile Robert e Dominique Vidal têm visões semelhantes: mais justo seria dizer Le Monde Diplomatique um periódico internacional nascido na França. A mencionada vocação internacional da revista se reflete também no cosmopolitismo da redação e do quadro "viajado" de intelectuais e jornalistas colaboradores. No núcleo parisiense, apenas para citar exemplos: o diretor Serge Halimi nasceu na Tunísia, o ex-redator-chefe Alain Gresh nasceu no Egito, a editora Mona Chollet é suíça, o novo redator-chefe adjunto Benoît Bréville estudou no Canadá, o ex-diretor Ignacio Ramonet é espanhol e viveu por muito tempo no Marrocos.

Se compreender o mundo, para Le Monde Diplomatique, é essencial, além da diversidade de perfis e trajetórias, o bureau francês valoriza titulações acadêmicas dentro e fora da redação: "Intelectuais escrevem no Le Monde Diplomatique - e todos os jornalistas de Le Monde Diplomatique são diplomados, são doutores". ${ }^{25}$ A partir da década de 1980, vale lembrar, foi pedido aos redatores para se diplomar e se especializar em certas áreas geográficas (África, América Latina e Oriente Médio, por exemplo) ou em determinados setores (direito internacional, literatura, tráfico e assim por diante).

$\mathrm{Na}$ imprensa tradicional, são versadas as expressões especialistas e/ou setoristas. Assim, Serge Halimi se dedica especialmente à cobertura relacionada a política e cultura norte-americana; Renaud Lambert, América Latina, Escócia, Inglaterra e Irlanda; Pierre Rimbert, Europa; Martine Bulard, a questões econômicas e Ásia; Laurent Bonelli, União Europeia; Benoît Bréville, Canadá e Estados Unidos; Alain Gresh, a política e cultura islâmica e Oriente Médio; Anne-Cécile Robert, a questões de direito internacional, União Europeia e África. Noutros tempos presentes na redação, Bernard Cassen e principalmente

\footnotetext{
24 Anne-Cécile Robert em entrevista à autora, no dia 14 de outubro de 2014.
}

25 Anne-Cécile Robert em entrevista à autora, no dia 14 de outubro de 2014. 
Ignacio Ramonet transitavam mais livremente no mapa-múndi, abordando questões relacionadas a Europa e América Latina, mas também ao destino de outros "destinos" mais distantes.

Para Anne-Cécile Robert, Le Monde Diplomatique estaria entre um jornal e uma revue. "Uma de nossas preocupações é trazer para o público leitor [leigo] as ideias do mundo acadêmico. E trazer para os intelectuais um pouco do mundo real". Atribui ao perfil internacional de Le Monde Diplomatique seu status de seriedade e de prestígio, justamente por não focar apenas a França, mas abordar países esquecidos pela imprensa tradicional - o que teria atraído leitores, de países diferentes, de realidades diferentes, para assinar a edição francesa, mas talvez também para iniciar uma edição própria da revista. "Le Monde Diplomatique é, voilà, uma instituição".

A editora considera a revista como uma tribuna para intelectuais de diversas nacionalidades e diversos repertórios - incluindo sindicalistas, militantes, estudantes. Uma revista internacional mas, na sua expressão très française. Isto é, como expressão da cultura francesa e da universalidade. Nas suas palavras:

A França ficou marcada pela Revolução Francesa, com essa ideia de que nós podemos portar um ideal universal de justiça, de fraternidade, de direitos humanos. Universal, por se referir ao mundo inteiro. E talvez Le Monde Diplomatique seja muito francês nesse sentido, por portar esse ideal do universal, isto é, a ideia de que todos os povos finalmente têm essa ideia comum, esse fim comum de progredir e de fazer avançar os valores. Por muito francês, podemos dizer, tem esse desejo de fazer progredir esses valores universais e, também, de dar a palavra aos intelectuais do mundo inteiro. $^{26}$

Para Serge Halimi, as edições internacionais são a prova de uma mensagem universalista do Monde Diplomatique. Como diretor da revista francesa, o jornalista atribui o sucesso das edições internacionais presentes na América Latina à expertise e à sofisticação das análises, "pois talvez as redações desses países não têm os elementos para permitir fazer as pesquisas sobre o norte da África ou o Oriente Médio". ${ }^{27}$

À expressão de Robert, Halimi acrescenta:

Sim, mas é um jornal très français que publica um discurso do presidente Rafael Correa em Paris, quando o resto da imprensa não aborda. Um jornal très français que publica um texto do subcomandante Marcos. Um jornal

26 Anne-Cécile Robert em entrevista à autora, no dia 14 de outubro de 2014.

27 Serge Halimi em entrevista à autora, no dia 28 de novembro de 2014. 


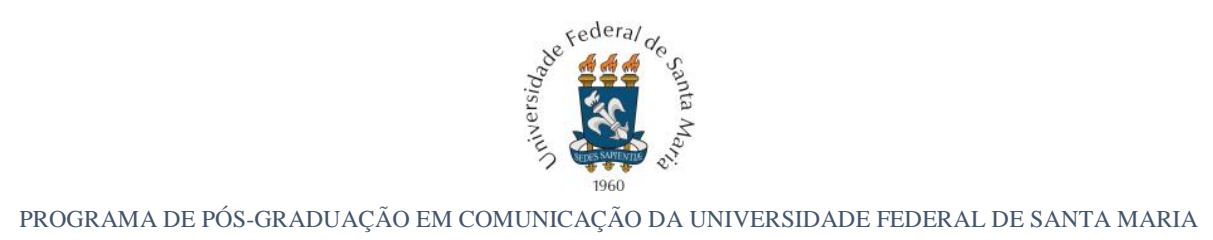

très français que foi muito solidário aos grandes combates da esquerda latino-americana, notavelmente no momento do golpe no Chile, contra Salvador Allende, ou do golpe na Argentina, três anos mais tarde. Um jornal que se interessava pelo Brasil, num momento em que poucos lembravam do país. Nós nos interessamos pelo Brasil antes ainda que se tornasse um país emergente - enquanto outros só se interessam por países que se tornam um ator no mercado ou uma economia potencial, para depois descobrir que há uma sociedade que vive ali. ${ }^{28}$

Entre tribuna intelectual e instituição, entre jornal e revue teórica, entre internacional e très français, aos olhos de seus editores, Le Monde Diplomatique defende um jornalismo reflexivo, não événementiel no fluxo dos acontecimentos. Esse se firmou como o principal asset a inspirar suas edições internacionais mundo afora.

\section{CONSIDERAÇÕES FINAIS}

Este artigo se propôs a abordar criticamente o processo de internacionalização de Le Monde Diplomatique, marcando diretrizes e fragilidades de suas edições internacionais, a compor uma experiência única na imprensa contemporânea. Em tempo, vale lembrar que estas breves páginas correspondem a apenas um trecho da tese de doutorado desenvolvida na Faculdade de Filosofia, Letras e Ciências Humanas da Universidade de São Paulo - tese esta que analisa, entre outras questões, o papel dos intelectuais participantes do magazine.

Desde 1954, quatro intelectuais passaram pela direção de Le Monde Diplomatique: entre 1954 e 1972, o diplomata húngaro François Honti (1900-1974); entre 1973 e 1990, o jornalista francês Claude Julien (1925-2005); entre 1990 e 2008, o sociólogo espanhol Ignacio Ramonet (1983-); e desde 2008 até o presente, o escritor francês Serge Halimi (1955-).

Delineou-se assim a linha editorial da publicação, que oscila entre uma revista de atualidades e uma revue acadêmica, com artigos e ensaios longos, marcados por muitas notas, cronologias, dossiês, glossários, índices e referências bibliográficas. A partir de textos elaborados, assinados por escritores e editores especializados, Le Monde Diplomatique quer ultrapassar os almanaques de atualidades e as antologias efêmeras do cotidiano.

Nas suas páginas escreveram importantes intelectuais contemporâneos, de diversas áreas e diferentes nacionalidades, como Edward Said (1935-2003), Eric Hobsbawm (19172012), Florestan Fernandes (1920-1995), Herbert Marcuse (1898-1979), Herbert Schiller (1919-2000), Jean Baudrillard (1929-2007), José Saramago (1922-2010), Julio Cortázar

\footnotetext{
28 Serge Halimi em entrevista à autora, no dia 28 de novembro de 2014.
} 
(1914-1984), Jüngen Habermas, Pierre Bourdieu (1930-2002), Stéphane Hessel (1917-2013), Tony Judt (1948-2010), entre muitos outros.

Firmou-se nessas rubricas e nessas ideias a marca da revista, que almeja oferecer uma visão alternativa, uma mirada crítica dos acontecimentos atuais, um ponto de vista singular, uma perspectiva atilada do jogo das relações internacionais, um outro olhar ou, na expressão preferida pelos editores franceses, uma manière de voir.

Le Monde Diplomatique - ou "o mundo diplomático" - tem um perfil especialmente voltado para questões internacionais. Além do caráter "cosmopolita" de seus intelectuais, destacam-se a ênfase na cobertura de política internacional e a presença de edições internacionais por mais de 40 países.

Diria que não é possível compreender, partindo do ponto de vista do mercado, a dimensão alcançada por Le Monde Diplomatique com suas edições internacionais - afinal, o magazine não dispõe de estratégias de mercado e, além de tudo, posiciona-se contra a lógica de mercado. Entretanto, é possível compreender o alcance de Le Monde Diplomatique além das fronteiras francesas a partir do prestígio que lhe é outorgado por seus leitores, entre jornalistas, acadêmicos e ativistas - leitores estes que decidem investir na ideia de levar o selo Le Monde Diplomatique a seus países.

Assim, é possível afirmar que, aos olhos de seus intelectuais e de seus leitores, Le Monde Diplomatique conquistou prestígio internacional por três razões capitais ao longo de sua trajetória: o viés analítico de suas edições; a relevância de seus autores, tanto jornalistas quanto intelectuais, versando sobre temas de interesse internacional; e a crítica aos dilemas contemporâneos na intrincada globalização neoliberal.

\section{REFERÊNCIAS BIBLIOGRÁFICAS}

AGRIKOLIANSKY, Eric; FILLIEULE, Olivier; MAYER, Nonna (Orgs.). L'altermondialisme en France: la longue histoire d'une nouvelle cause. Paris: Flammarion, 2005.

"Aux origines de l'altermondialisme français". In: AGRIKOLIANSKY, Eric ; FILLIEULE, Olivier ; MAYER, Nonna (Orgs.). L'altermondialisme en France: la longue histoire d'une nouvelle cause. Paris: Flammarion, 2005, p. 12-42.

"Du tiers-mondisme à l'altermondialisme: Genèse(s) d'une nouvelle cause". In: AGRIKOLIANSKY, Eric ; FILLIEULE, Olivier ; MAYER, Nonna (Orgs.). L'altermondialisme en France: la longue histoire d'une nouvelle cause. Paris: Flammarion, 2005, p. 43-73. 
; GOBILLE, Boris. "El activismo altermundialista en Europa”. In: Revista de Sociología. Santiago: Facultat de Ciencias Sociales, Universidad de Chile, n. 25, 2011, p. 139-161.

CHALIAND, Gérard. Mitos revolucionários do Terceiro Mundo. Rio de Janeiro: Francisco Alves, 1977. Traduzido por Antonio Guimarães Filho.

COCKBURN, Alexander. “Le complot du 11-Septembre n'aura pas lieu”. In: Le Monde Diplomatique, Paris, dezembro de 2006, p. 3.

. "Los paranoicos del complot". In: Le Monde Diplomatique Edición Cono Sur, Buenos Aires, n. 90, dezembro de 2006.

DERRIDA, Jacques. "Una Europa de la esperanza”. In: Le Monde Diplomatique Edición Cono Sur, Buenos Aires, n. 65, novembro de 2004, p. 36-37.

HARVEY, Nicolas. Le Monde Diplomatique: un concept éditorial hybride au confluente du journalisme, de l'université et du militantisme. Rennes: Université de Rennes I. Tese de doutorado em ciência política.

HOBSBAWM, Eric. Tempos fraturados: cultura e sociedade no século XX. São Paulo: Companhia das Letras, 2013. Traduzido por Berilo Vargas.

HOLZINGER, Flavie. "Le Monde Diplomatique d'Ignacio Ramonet de 1991 à 2008: analyse géopolitique des représentations". Paris: Université Paris VIII - Vincennes-Saint Denis, 2014. Tese de doutorado em geopolítica.

JULIEN, Claude. “Assassinat”. In: Le Monde Diplomatique, Paris, dezembro de 1986, p. 1 e p. 15.

LACROIX, Bernard. "Le retournement de Mai 68”. In: Le Monde Diplomatique, Paris, maio de 2008 , p. 31.

LE MONDE DIPLOMATIQUE. “'Le Monde diplomatique' en allemand”. In: Le Monde Diplomatique, Paris, maio de 1995, p. 2.

“Une édition en espagnol du 'Monde diplomatique”. In: Le Monde Diplomatique, Paris, fevereiro de 1979, p. 22.

. “Qui sont les lecteurs du Monde diplomatique?”. In: Le Monde Diplomatique, Paris, novembro de 1985 , p. 25.

LÖWY, Michael. Revoluções. São Paulo: Boitempo Editorial, 2009.

RABADÁN, Pablo López. La estrategia de encuadre en la prensa de referencia internacional: el caso de Le Monde Diplomatique. Madri: Universidad Rey Juan Carlos, 2009. Tese de doutorado em ciências da comunicação.

RAMONET, Ignacio. "Notre ami Claudio Cortés Garcia assassiné au Mexique". In: Le Monde Diplomatique, Paris, dezembro de 1998, p. 2. 
KOHLER, Heliane; RODRIGUES, Helenice (Orgs.). Travessias e cruzamentos culturais. Rio de Janeiro: Editora FGV, 2008, p. 23-45.

SZCZEPANSKI-HUILLERY, Maxime. Du diplomate au citoyen. Études sur la politisation du Monde diplomatique et de ses lecteurs (1954-2008). Amiens: Université de Picardie, 2009. Tese de doutorado em ciência política.

VIDAL, Dominique. “Cinquante voix de la résistance". In: Le Monde Diplomatique, Paris, junho de 2004, p. 29.

“'L'Internationale Du 'Diplo"”. In: Le Monde Diplomatique, Paris, novembro de 2006, p.

27.

Original recebido em: 08/06/2015

Aceito para publicação em: 18/08/2016

Juliana Sayuri Ogassawara

Jornalista, doutora em História Social pela Universidade de São Paulo (USP) e pósdoutoranda pela Universidade Federal de Santa Catarina (UFSC). É autora de Diplô: Paris -

Porto Alegre (Com-Arte, 2016) e Paris - Buenos Aires (Alameda, 2017, no prelo)

Esta obra está licenciada sob uma Licença Creative Commons. 